\title{
Development and evaluation of multiparticulate biphasic system for the treatment of circadian diseases
}

\author{
Sarah Moherdaui Martinss, 1,2, , Vinicius Müller², Vanderson Galan², Fabio Pinheiro de Souza², \\ Itamar Francisco Andreazza ${ }^{3}$, Maurício Ferreira da Rosa ${ }^{1}$
}

\begin{abstract}
${ }^{1}$ Department of Pharmacy, State University of the West of Paraná, Cascavel, Brazil, ${ }^{2}$ Department of Research, Development and Innovation, Prati-Donaduzzi and Cia Ltda, Toledo, Brazil; ${ }^{3}$ Department of Pharmacy, Federal University of Parana, Curitiba, Brazil
\end{abstract}

\begin{abstract}
Multiparticulate systems have biopharmaceutical advantages when compared to the monolithic systems, once they allow different patterns of drug release and can be used in different treatments. The aim of the present work was to develop a biphasic controlled release delivery system, using propranolol hydrochloride (PROP) that can be used for the treatment of circadian diseases. This system was obtained by the combination of cellulosic polymers hydroxypropyl methylcellulose (HPMC) and ethylcellulose (EC) in a $2^{2}$ factorial experimental design, which allowed the optimization of the development stage. The pellets produced and used in biphasic formulations were evaluated for physical and chemical characteristics and presented acceptable results. The immediate fraction obtained showed the complete release in $30 \mathrm{~min}$ while the others kept the release of the drug for $24 \mathrm{~h}$. This study showed that the combination of beads with different releasing characteristics allowed to obtain different release profiles, which can be modulated according to the pathological needs, especially with regard to circadian diseases that suffer alterations throughout the day.
\end{abstract}

Keywords: Chronotherapy. Biphasic Release. Pellets. Cellulosic Polymers. Experimental Design.

\section{INTRODUCTION}

Multiparticulate systems are, by definition, a functional unit that contains the drug subdivided into pellets, granules, mini-pills or a combination of these (Zerbini, Ferraz, 2011). Pellets are spherical units constituted by agglomeration of drugs and excipients, with diameters ranging from 100 to $2000 \mu \mathrm{m}$, and may act as an intermediate for the production of sachets, capsules or tablets. Multiparticulate systems have advantages when compared to classical unitary systems: better distribution on the gastrointestinal tract (GIT), lack of influence of gastric emptying, lower risk of systemic toxicity and local irritation, as well to enable the obtaining of customized release forms (Ghebre-Selassie, 1989; Bauer et al., 1998; Pezzini, Silva, Ferraz, 2007; Aulton, Ortega, 2008; Kulkarni, 2010; Lachman, Lieberman, Kaning, 2013).

\footnotetext{
*Correspondence: S. M. Martins. Programa de Pós-Graduação em Ciências Farmaceuticas, Universidade Estadual do Oeste do Paraná. R. Universitária, 2069, Jd Universitário, 85819-110 Cascavel, Paraná, Brasil. E-mail: sarahmoherdaui@hotmail.com
}

In an ideal therapeutic regimen, the drug must reach the site of action quickly and its release must be constant during the treatment. Some drugs have naturally a long time of action, requiring only one daily dosing to maintain the adequate plasma levels. However, many others must be administered repeatedly, which may result in a seric drug fluctuation in intervals prior to the next administration (Aulton, Ortega, 2008; Bruschi, 2015). As an alternative to such inconvenience, it has been increasingly sought the use of systems capable of modulating the release of the drug in a gradual manner, providing a reduction in the frequency of administration, less fluctuation in plasma concentrations of the drug, less side effects and greater adherence to treatment (Lopes, Lobo, Costa, 2005; Villanova, Oréfice, Cunha, 2010).

On the types of modified release existing in the pharmaceutical context, the biphasic delivery system stands out, which is intended to release the drug at different stages of release, a fraction of initial release (fast) and a modified release (slow) and the first fraction may be represented by the immediate release, while the second by extended release (Jha, Rahman, Rahman, 2011). 
Representing the pharmacotherapeutic agent candidates and attractive for this type of release, one has the antihypertensive drugs, antihistamines, analgesics, antipyretics and anti-allergic. These drugs are used for the treatment of diseases known as circadian that have oscillations according to the period of the day, since the human organism is complex and is constantly subject to physiological and biochemical changes, such as the case of hypertension, where the occurrence of manifestations related to cardiovascular complications occur predominantly in the early morning hours, period on which the blood pressure is higher (Londhe, Gattani, Surana, 2010; Ohdo, 2010; Jha, Rahman, Rahman, 2011; Lin, Kawashima, 2012; Verdecchia et al., 2012; Dallmann, Brown, Gachon, 2014).

To obtain a specific release system, it is often necessary the use of polymer-based coatings, being common in these cases the mixture of polymers with different characteristics and solubility properties, for example the association of cellulose derivatives hydroxypropyl methylcellulose (HPMC), with high water solubility, and ethyl cellulose (EC), with water-insoluble characteristics, widely used in pharmaceuticals in order to obtain modified drug release systems (Lopes, Lobo, Costa, 2005; Oliveira, 2007; Guerra-Ponce et al., 2016).

In cases in which are used the combination of polymers to obtain the desired release profile, it is extremely important the knowledge of its characteristics and influence in the formulation, in order to reduce the development time and the number of trials. Thus, several tools have been used to optimize the development phase, as the case of the use of the experimental design tool that provides more accurate information with a lower number of experiments. In the present scenario, the pharmaceutical industry seeks to increasingly reduce the development time and getting more robust processes that increase competitiveness in the market (Pisano, 1997; Singh, Kumar, Ahuja, 2005; Rubin et al., 2006; Lachman, Lieberman, Kaning, 2013).

The aim of the present study was to develop a biphasic controlled release delivery system with length of 24 hours, for the treatment of circadian diseases, using propranolol hydrochloride (PROP), a $\beta$-blocker drug widely used in heart diseases. Due to the peak concentration of 1-1.5 hour and the half-life of 4-6 hour, the active may be considered a strong candidate for developing a modified-release formulation (Brasil, $2010 b)$. For that, it was used a combination of cellulosic polymers for coating with HPMC-EC polymers associated with a $2^{2}$ factorial experimental design to the optimization of the development stage.

\section{MATERIAL AND METHODS}

\section{Material}

Propranolol hydrochloride, (PROP) (Iffect Chempar Co. Ltda, India), polyvinylpyrrolidone K30 -Plasdone ${ }^{\circledR}$ K30, (PVP K30) (Ashland, USA); sucrose inert beads 25-30 mesh, (EIS) (JRS Pharma, Germany); ethylcellulose N45 -Ethoce ${ }^{\circledR}$ N45 (EC) and hydroxypropyl methylcellulose 5cps -Methoce ${ }^{\circledR}$ E5 LV, (HPMC) (Colorcon, USA); talc (Magnesita, Brasil) and Triethyl citrate (TEC) (Vertelus, USA). The raw materials and excipients used were kindly provided by Prati Donaduzzi Ltda Pharmaceutical Industry, Brazil.

\section{Compatibility study}

The interaction between the drug and the excipients were evaluated through analysis of Differential Scanning Calorimetry (DSC) and Fourier Transform Infrared Spectroscopy (FTIR). Analyses were performed on samples containing pure PROP, binary mixtures of PROP with excipients in the proportion 1:1, mixture of the placebo used in the final formulation and PROP in equal proportion (1:1) and also the pellets of the best formulation obtained at the end of the development stage.

DSC analyses were performed using a DSC-1 (Mettler Toledo) and the results were processed in $\mathrm{Star}^{\circledR}$ software, licensed by Mettler-Toledo ${ }^{\circledR}$. The analyses of FTIR were performed by using a Infrared Fourier Transform Spectrophotometer (Spectrum 400®, Perkin - Elmer $\left.^{\circledR}\right)$ with accessory of attenuated total reflectance probe (ATR) to mid-infrared.

\section{Development of the immediate release fraction}

For choosing the bonding agent employed in the attainment of pellets 4 formulations (A - D) were prepared using the solution PVP K30 or HPMC polymers in different proportions. An initial loading of $1500 \mathrm{~g}$ of EIS was used in the preparation of the formulations. The composition of formulations are shown in Table I.

For formulation A, the EIS was coated with an alcohol solution, a mixture of PROP, PVP K30 and talc. For the formulations B, C and D, EIS were coated with a hydroalcoholic solution $(1: 1, \mathrm{w} / \mathrm{w})$ containing the mixture of PROP, HPMC and talc. The coating process of all formulations were performed in fluidized bed (Bosch Hüttlin ${ }^{\circledR}$ Unilab $\left.{ }^{\circledR}\right)$, following the parameters: Inlet air flow rate $=250 \mathrm{~m}^{3} / \mathrm{h}$, inlet air temperature $=40-45^{\circ} \mathrm{C}$ and product temperature $=37-39^{\circ} \mathrm{C}$. After completion of the 
Development and evaluation of multiparticulate biphasic system for the treatment of circadian diseases

TABLE I - Composition of formulations for choosing bonding agent

\begin{tabular}{lcccc}
\hline Composition & A (\%) & B (\%) & C (\%) & D (\%) \\
\hline PROP & 11.32 & 11.32 & 11.32 & 11.32 \\
PVP K30 & 1.89 & - & - & - \\
HPMC & - & 0.94 & 2.83 & 3.77 \\
Talc & 2.83 & 2.83 & 2.83 & 2.83 \\
EIS & 29.25 & 30.19 & 28.30 & 27.36 \\
Isopropyl Alcohol & 54.72 & 27.36 & 27.36 & 27.36 \\
(AIS) & & & & \\
Purified Water & - & 27.36 & 27.36 & 27.36 \\
\hline Total & 100.00 & 100.00 & 100.00 & 100.00 \\
\hline
\end{tabular}

coating process, the pellets were dried at $40{ }^{\circ} \mathrm{C}$ for $30 \mathrm{~min}$.

The yield ( $\mathrm{R} \%$ ) of the formulations was calculated as:

$\mathrm{R}(\%)=\frac{\text { weight obtained from coated pellets }}{\text { initial weight }(\text { excipients }+ \text { PROP })} \times 100$

From the initial formulations, the one with the highest yield and performance was used for developing the pellets. The formulation chosen, initial weight of $1500 \mathrm{~g}$ of pellets coated with PROP, was subjected to seal coating, prepared from an aqueous colloidal dispersion of HPMC $(8.20 \%, \mathrm{w} / \mathrm{w})$. The following parameters were followed: Inlet air flow rate $=250 \mathrm{~m}^{3} / \mathrm{h}$, inlet air temperature $=45-50$ ${ }^{\circ} \mathrm{C}$, product temperature $=39-41^{\circ} \mathrm{C}$, atomization pressure $=1.20 \mathrm{bar}$, microclimate pressure $=0.25 \mathrm{bar}$, atomization nozzle diameter $=1.0 \mathrm{~mm}$, air cap diameter $=12 \mathrm{~mm}$, and atomization rate of the coating suspension $=10-14 \mathrm{~g} /$ $\mathrm{min}$. After the coating process, the pellets were dried for 30 min at $40{ }^{\circ} \mathrm{C}$.

\section{Development of the modified release fraction}

To optimize the development of PROP pellets for modified release, experiments were performed based on a full factorial design with two factors in two levels $\left(2^{2}\right)$ and triplicate on the center point, resulting in 7 modified release formulations. The variables studied were the concentrations of HPMC and EC coating polymers in the third coating layer of the pellets as well as HPMC x EC interaction in response of the PROP release time. For each factor (HPMC and EC), two levels were used: -1 (low) and +1 (high), according to Table II.

The experiments were performed randomly and with triplicate at the center point. The factorial matrix used for the design of experiments is shown in Table III. The
TABLE II - HPMC and EC variables and levels (-1, 0 and 1) used in the factorial experimental design $2^{2}$

\begin{tabular}{lccc}
\hline \multirow{2}{*}{ Variables } & \multicolumn{3}{c}{ Levels } \\
\cline { 2 - 4 } & $\mathbf{- 1}$ & $\mathbf{0}$ & $\mathbf{1}$ \\
\hline HPMC (mg) & 2.00 & 4.00 & 6.00 \\
EC (mg) & 10.00 & 20.00 & 30.00 \\
\hline
\end{tabular}

experimental data obtained from this $2^{2}$ factorial design were processed using the Design Expert ${ }^{\circledR} 7.1 .3$ software. The significance of the factors and model validation were confirmed by the analysis of variance (ANOVA) and linear regression.

TABLE III - Factorial $2^{2}$ planning for the codified variables: HPMC (mg) and EC (mg). Experiments performed randomly and with triplicate at the center point

\begin{tabular}{cccc}
\hline \multirow{2}{*}{ Formulation } & \multirow{2}{*}{ Sequence } & \multicolumn{2}{c}{ Variables codified } \\
\cline { 3 - 4 } & & HPMC (mg) & EC (mg) \\
\hline F1 & 4 & -1 & -1 \\
F2 & 3 & 1 & -1 \\
F3 & 5 & -1 & 1 \\
F4 & 2 & 1 & 1 \\
F5 & 6 & 0 & 0 \\
F6 & 1 & 0 & 0 \\
F7 & 7 & 0 & 0 \\
\hline
\end{tabular}

In order to obtain modified release pellets, it was used as starting point PROP pellets with seal coating, an initial amount of $1500 \mathrm{~g}$ for batches. The coating of the F1 to F7 formulations was carried out from a hydroalcoholic solution (ethanol: water 9:1 w/w) of the EC, HPMC and TEC mixture, as the amounts described in Table IV. The following parameters were followed: inlet air flow rate $=250 \mathrm{~m}^{3} / \mathrm{h}$, inlet air temperature $=$ $40-45{ }^{\circ} \mathrm{C}$ and product temperature $=35-37^{\circ} \mathrm{C}$. After completion of the coating process, the pellets were dried at $40{ }^{\circ} \mathrm{C}$ for $30 \mathrm{~min}$.

\section{Obtaining the multiparticulate biphasic system of PROP}

Different proportions of the immediate and modified release pellets obtained were placed in hard gelatin capsules \#1 for evaluation and comparison of the dissolution profiles, resulting in the F8 and F9 formulations. The final concentration of $80 \mathrm{mg}$ PROP was maintained in each of the formulations. 
TABLE IV - Formulation for obtaining modified release pellets

\begin{tabular}{lccccccc}
\hline Composition & F1 (mg) & F2 (mg) & F3 (mg) & F4 (mg) & F5 (mg) & F6 (mg) & F7 (mg) \\
\hline Pellets Sealed & 337.60 & 337.60 & 337.60 & 337.60 & 337.60 & 337.60 & 337.60 \\
EC & 10.00 & 10.00 & 30.00 & 30.00 & 20.00 & 20.00 & 20.00 \\
HPMC & 2.00 & 6.00 & 2.00 & 6.00 & 4.00 & 4.00 & 4.00 \\
TEC & 1.20 & 1.60 & 3.20 & 3.60 & 2.40 & 2.40 & 2.40 \\
Alcohol 96 ${ }^{\circ} \mathrm{GL}^{*}$ & 682 & 682 & 682 & 682 & 682 & 682 & 682 \\
Purified Water* & 68.20 & 68.20 & 68.20 & 68.20 & 68.20 & 68.20 & 68.20 \\
\hline Total & 350.80 & 355.20 & 372.80 & 377.20 & 364.00 & 364.00 & 364.00 \\
\hline
\end{tabular}

* Solvent evaporates during the process.

\section{Determination of drug content}

PROP content in the pellets was determined using a UV/Vis spectrophotometer (Varian Cary ${ }^{\circledR} 50$ ). A pellet mass equivalent to $25 \mathrm{mg}$ PROP was weighed and transferred to a $25 \mathrm{~mL}$ volumetric flask, added with 2 $\mathrm{mL}$ methanol and the flask was taken to ultrasonic bath (Unique, model C3300) for $40 \mathrm{~min}$. Subsequently, more $12.5 \mathrm{~mL}$ methanol was added and the flask was taken to ultrasonic bath for another $20 \mathrm{~min}$. The volumetric flask volume was filled with the same solvent. From this solution, an aliquot of $2.0 \mathrm{~mL}$ was transferred to a $25 \mathrm{~mL}$ volumetric flask and the volume was completed with $\mathrm{HCl}$ $0.01 \mathrm{~N}$. All solutions were filtered through a quantitative cellulose filter and the final concentration was $0.08 \mathrm{mg} /$ $\mathrm{mL}$ PROP. The samples were analyzed by UV/VIS spectrophotometer at $289 \mathrm{~nm}$ and trials were performed in triplicate.

\section{Dissolution profile}

Dissolution of PROP pellets was performed by a methodology validated in our laboratory according to Resolution n. 899 of ANVISA (Brasil, 2003), in USP dissolutor apparatus 1 (basket) Sotax ${ }^{\circledR}$ Semiautomatic, coupled to the automatic samples collector, using hydrochloric acid solution ( $\mathrm{HCl} 0.01 \mathrm{~N}, 1000 \mathrm{~mL}$ ) as dissolution medium at $37.0 \pm 0.5^{\circ} \mathrm{C}$. The collections and respective readings occurred on-line at time intervals of $5,10,15,20,30,60$ and 90 min for the pellets with active coating and sealing coating and at intervals of 30, 60, 90 , 120, 180, 240, 360, 480, 600, 720, 960, 1200 and 1440 min for the modified pellets of biphasic release. For F3 the analysis time has been extended to $2400 \mathrm{~min}$. Samples were analyzed by spectrophotometry in the ultraviolet region at $289 \mathrm{~nm}$ using UV/Vis spectrophotometer to determine the concentration of drug present.

The dissolution efficiency (DE) was calculated by the method described by Khan (1975) and the similarity factor (f2) was evaluated in order to compare the similarity between the percentage of drug dissolved among the formulations, according to Costa, Lobo (2001); Maggio, Castellano, Kaufman (2008), where the dissolution of a number of samples (n) of reference (Rt) and test $(\mathrm{Tt})$ products are compared in a certain period of time:

$\mathrm{f} 2=50 * \log \left\{\left[1+(1 / \mathrm{n}) \sum_{\mathrm{t}-1}^{\mathrm{n}}(\mathrm{Rt}-\mathrm{Tt})^{2}\right] 0^{-0,5} * 100\right\}$

For the dissolution curves to be considered similar, the $f 2$ value should be between 50 and 100 (Brasil, 2010a).

\section{Characterization of the pellets obtained}

Pellets that presented the desired release properties to obtain the biphasic formulations of PROP were analyzed for granulometric evaluation, apparent (AD) and compacted (CD) density, friability, loss by drying, sphericity and evaluation of the external morphology.

For the granulometric evaluation, $100.0 \mathrm{~g}$ samples were subjected to the vibrational agitation of $15 \mathrm{~Hz}$ for $10 \mathrm{~min}$ in a sieve Impact Test Sieve Shaker SV001, using $18,20,25,30$ and 35 mesh. The results were expressed in percentage of pellet mass retained in each mesh.

The evaluation of the pellet density was obtained after evaluation of a sample of $50 \mathrm{~g}$ in $250 \mathrm{~mL}$ graduated measuring cylinder, subjected to 200 beats, with the aid of a compaction densimeter Pharma Test PT-TD200 (Mehta et al., 2012). The friability $(\% \mathrm{~F})$ was determined according to European Pharmacopoeia (2011), by weighing the mass loss after 960 horizontal oscillations (240 oscilations per minute for $4 \mathrm{~min}$ ) and determined according to equation (3) (Mehta et al., 2012):

$$
F(\%)=\frac{\text { initial weight }\left(\mathrm{w}_{1}\right)-\text { final weight }\left(\mathrm{w}_{2}\right)}{\text { initial weight }\left(\mathrm{w}_{1}\right)} \times 100
$$


The moisture content $(n=3)$ was determined in an infrared moisture balance (Mettler-Toledo ${ }^{\circledR} \mathrm{HB} 43-\mathrm{S}$ Halogen), weighing samples of $2.0 \mathrm{~g}$ at the maximum temperature of $105^{\circ} \mathrm{C}$ till constant mass. The percentage referring to the weight loss was considered as the moisture content of the sample.

Sphericity (S) of the pellets was calculated according to Lovgren and Lundberg (1989), through measurement of the length and width of the bidimensional image of the pellets using 20 units. The format was expressed as a sphericity percentage, where $100 \%$ corresponds to a perfect circle.

The evaluation of the external morphology of the pellets was performed through images obtained by scanning electron microscopy (SEM) (Shimadzu ${ }^{\circledR}$, SS 550 model), at accelerating voltage of $15.0 \mathrm{kV}$ and probe current of 4.0 pA. Samples were placed in a metallic sample holder, fixed with carbon tape, and subsequently coated with a thin layer of gold, using a current of $4 \mathrm{~mA}$ for $3 \mathrm{~min}$.

\section{RESULTS AND DISCUSSION}

The study of compatibility between the active and the excipients is of fundamental importance, since it can reduce or predict possible complications during the development of the drug (Aulton, Ortega, 2008).

The DSC curves obtained for the PROP and the binary mixtures are showed in Figure 1. The thermogram obtained for the PROP showed a pronounced endothermic peak at $163.73{ }^{\circ} \mathrm{C}$ characteristic of its melting point (Sahoo et al., 2008; Farmacopeia Brasileira, 2010). The thermograms obtained from the binary mixtures between excipients and PROP showed no significant alterations of the endothermic peak, indicating a good compatibility between the PROP and the chosen excipients. Samples of the placebo and PROP mixture and the final formulation of PROP also showed no alterations of these peaks, indicating that even after the use of excipients and the preparation process, the characteristics of the drug remained unaltered.

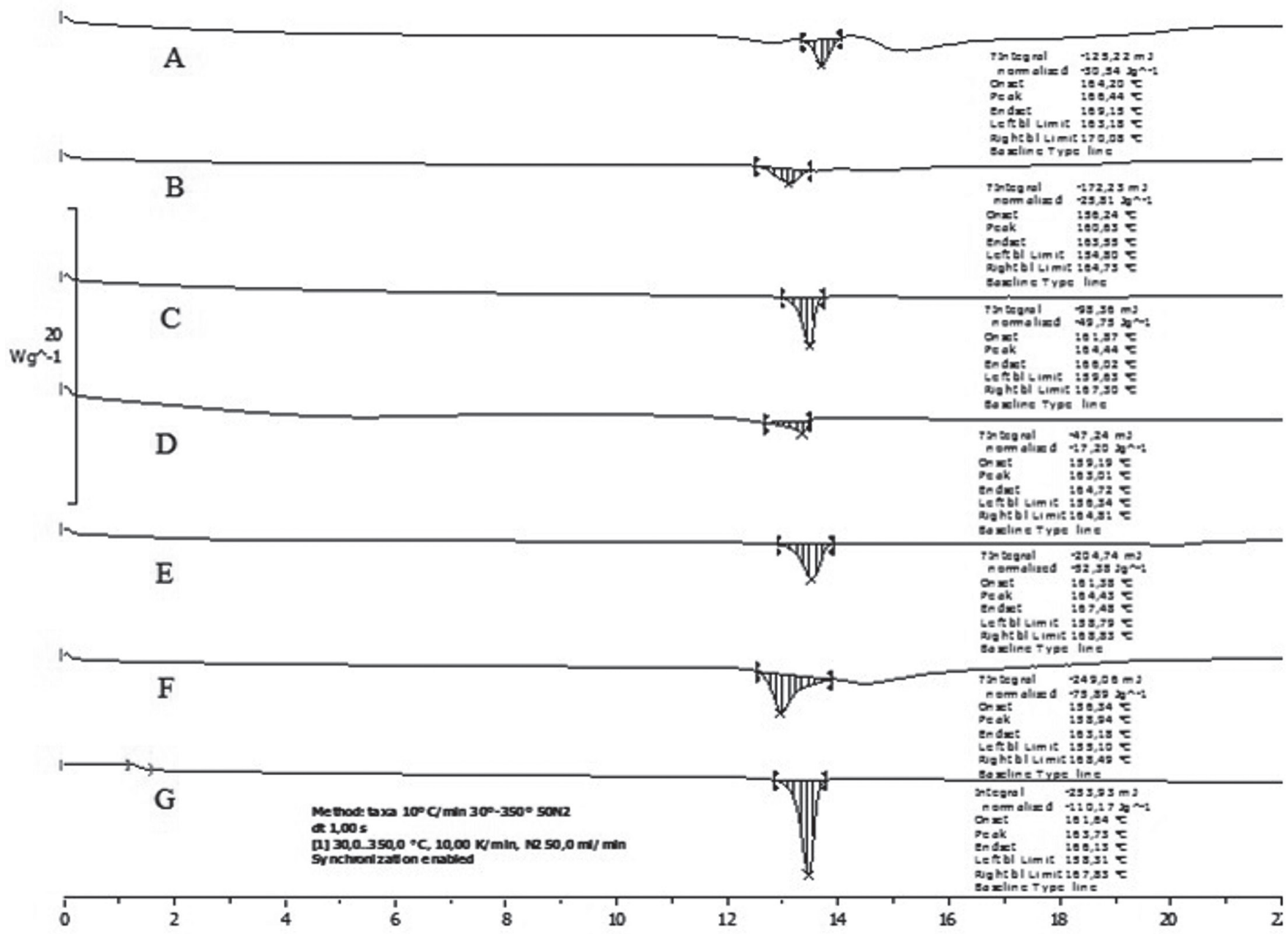

FIGURE 1 - Thermal analysis of DSC A) Final formulation of PROP; B) PROP + Placebo of the pellets; C) PROP + talc; D) PROP + PVP K30; E) PROP + HPMC; F) PROP + EIS; G) PROP. 
Although the DSC analysis is the most used in compatibility studies, the interpretation of data provided are not always easy and can lead to misinterpretation of results. Moreover, the results obtained at high temperatures may not be relevant when it comes to room and/or storage temperature being often advisable to use confirmatory techniques, such as FTIR (Liltorp et al., 2011; Tiţa et al., 2011). The results obtained in FTIR analysis are shown in Figure 2. Pure propranolol showed characteristic peaks between $3650-3200 \mathrm{~cm}^{-1}$ (-OH stretch), 3500-3100 $\mathrm{cm}^{-1}$ (N-H stretch), 3100-3000 $\mathrm{cm}^{-1}$ (styrene $-\mathrm{CH}$ of aromatics), $1600-1475 \mathrm{~cm}^{-1}$ (aryl $\mathrm{C}=\mathrm{C}$ stretch), 1240 and $1030 \mathrm{~cm}^{-1}$ asymmetric and symmetrical $\mathrm{O}-\mathrm{CH}_{2}$ stretches, respectively, and at $798 \mathrm{~cm}^{-1}$ due to alpha-substituted naphthalene. Peaks corresponding to pure propranolol in final formulation confirm the absence of interaction among samples analyzed, since no significant alterations are observed (Srikanth et al., 2012; Saeedi, Morteza-Semnani, Sagheb-Doust, 2013).

Tests from A to D, as described in Table 4, were performed in order to define the most suitable bonding agent in the attainment of immediate release pellets. After obtaining formulation $\mathrm{A}$, it was observed a yield of $85.7 \%$ and $86.0 \%$ PROP content of the pellets, with the presence of many pellets agglomerated and fine powder inside the equipment during the process, suggesting that the increase in bonding agent, PVPK 30, in the attempt to correct the loss of powder, would worsen the agglomeration of the pellets while its decrease would cause the increase of powder loss. For the formulation B, it was obtained $94.20 \%$ yield and PROP content of $84.40 \%$, in this case, it was possible to observe a considerable loss of the active

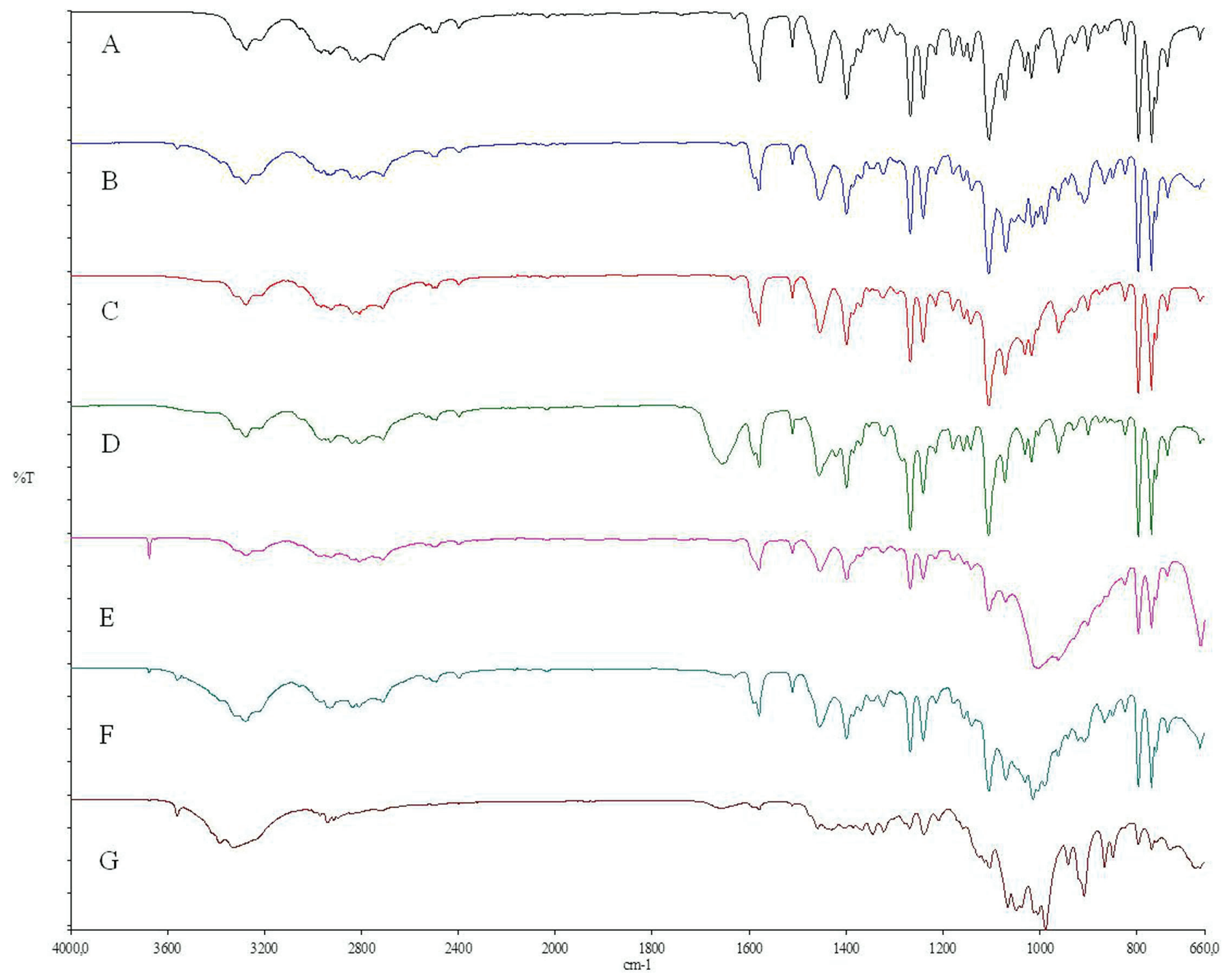

FIGURE 2 - Infrared absorption spectrum A) PROP; B) PROP+EIS; C) PROP + HPMC; D) PROP + PVP K30; E) PROP + Talc; F) PROP + Placebo; G) Final formulation of PROP. 
compound, which was confirmed with the presence of large amounts of fine powder inside the fluidized bed. Even obtaining a yield above $90.00 \%$ in the test, the PROP content was lower than expected.

In the attempt to solve the problem of powder loss during the coating process of $\mathrm{B}, \mathrm{C}$ and $\mathrm{D}$, tests were made with increasing amount of the HPMC bonding agent to 2.83 and $3.77 \%$ respectively. In test $\mathrm{C}$, it was obtained $98.70 \%$ yield and $99.20 \%$ content of PROP, while in D, $92.10 \%$ yield, and $98.90 \%$ content of PROP. Even with the high content presented in the two formulations, formulation D presented lower yield when compared to C. This is possibly because the high concentration of polymer applied may have favored the agglomeration of the pellets during the coating step. Thus, formulation $\mathrm{C}$ was selected for following the experiments, due to the best results in the requisites of yield and PROP content values within the expected. The results of yield and content of PROP are listed in Table V.

TABLE V - Results of yield and content of PROP found for the formulations from $\mathrm{A}$ to $\mathrm{D}$

\begin{tabular}{ccc}
\hline Formulation & Yield (\%) & PROP content (\%) \\
\hline A & 85.70 & 86.00 \\
B & 94.20 & 84.40 \\
C & 98.70 & 99.20 \\
D & 92.10 & 98.90 \\
\hline
\end{tabular}

To prevent contact of the drug present in the active coating with the functional coating, a sealing coating layer was applied onto the active coating pellets $(\mathrm{C})$, originating $\mathrm{C} 1$ in order to form a barrier between these two coatings and thus preventing the migration of the active compound to the functional coating and possible problems in the release and stability of the drug (McGinity, Felton, 2008). Besides protection against degradation, this coating allows the correction of defects and/or roughnesses that may exist on the surface of the pellets, allowing the functional coating to be distributed uniformly over the entire surface of the pellets (Prasad et al., 2013).

The modified release pellets were obtained through application of the functional coating, composed of EC and HPMC over the pellets containing seal coating (C1), in order to obtain a 24 -hour release profile (1440 $\mathrm{min})$. $\mathrm{EC}$ is a polymer derived from cellulose, which has a good capacity to form transparent films, flexible and resistant, however water-insoluble, while HPMC has high solubility in water therefore being much used as pore former in modified release coatings (Rowe, Sheskey, Quinn, 2009).

TEC was used as a plasticizing agent in a concentration of $10.00 \%$ in relation to the dry weight of the polymers, aiming to improve the flexibility characteristics of the film, to facilitate its distribution on the surface of the pellets and ensure homogeneity of the applied coating (Bauer et al., 1998).

For the evaluation of dissolution profile of the obtained pellets (Figure 3), it can be observed that $\mathrm{C}$ and $\mathrm{C} 1$ formulations showed an immediate release profile, since both formulations present average dissolution greater than $75.00 \%$ of the active substance within $30 \mathrm{~min}$ (Farmacopeia Brasileira, 2010), and the dissolution of C and $\mathrm{C} 1$, in $15 \mathrm{~min}$, of $98.16 \% \pm 1.13$ and $94.90 \% \pm 2.36$,

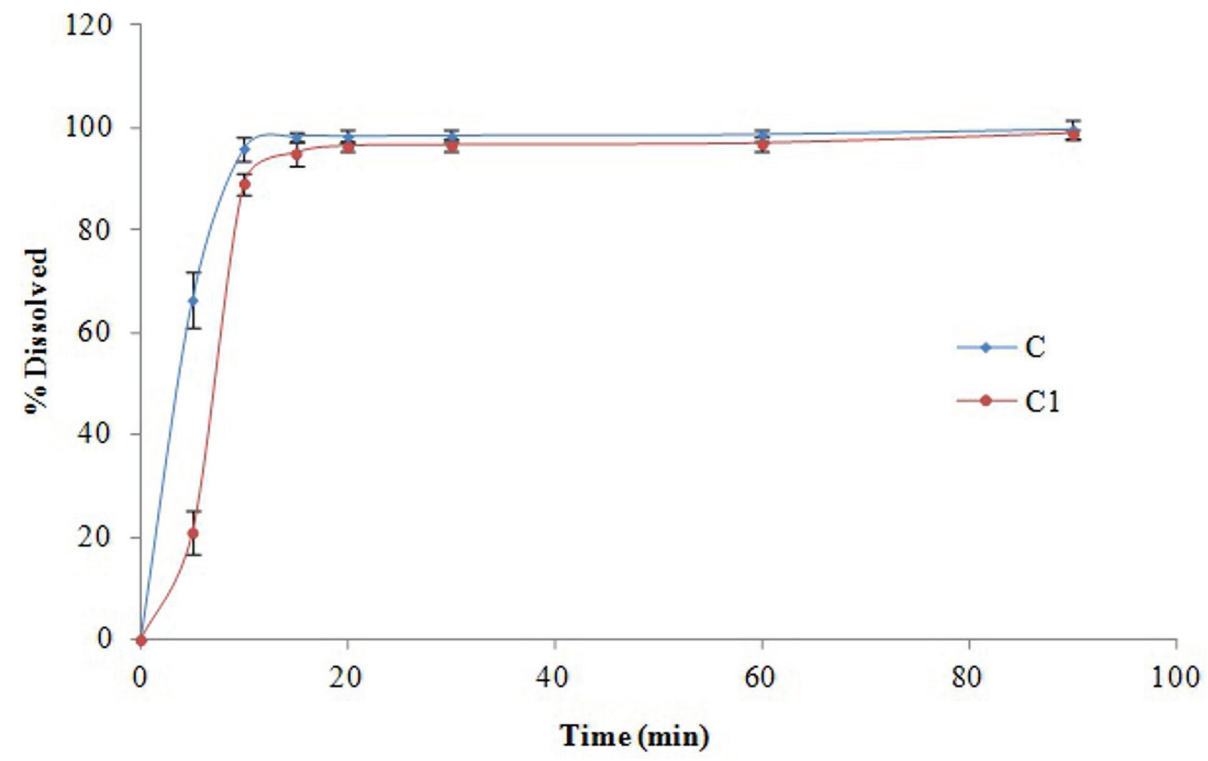

FIGURE 3 - Dissolution profiles of the pellets obtained in C and C1. 
respectively. However, even presenting an immediate release, the release profile of these formulations do not present similarity, since $f 2=37.9$.

The dissolution profiles obtained from the experimental design (Figure 4) show that F1 and F4 formulations achieve respectively $100.10 \%$ and $101.93 \%$ of the active compound released within 960 min, showing a 16-hour releasing profile. F2 formulation reaches more than $95.00 \%$ of drug release within $30 \mathrm{~min}$, releasing all the active compound loaded in up to $90 \mathrm{~min}$, classifying $\mathrm{C}$ as well as $\mathrm{C} 1$ in the category of the immediate release. F3 formulation releases only $84.20 \%$ of the amount of PROP present in the formulation in $1440 \mathrm{~min}$, indicating that it would take more than 24 hours to release all PROP loaded in the pellets, representing a very slow release profile.

On the other hand, the profiles obtained by the formulations F5, F6 and F7 indicate a 24-hour release profile, reaching the PROP releasing aim during this period. Thus, formulation F5 was randomly chosen to represent the fraction of modified release of the biphasic formulation.

For the formulations F8 $(20 \mathrm{mg} \mathrm{C} 1+60 \mathrm{mg} \mathrm{F} 5)$ and F9 (40 mg C1 + $40 \mathrm{mg} \mathrm{F}$ ), it was possible to obtain a biphasic release profile (Figure 5), so that F9 presented a faster release profile, when compared to F8 of up to about $600 \mathrm{~min}$, extending the release in both formulations for a period of 24 hours. The dissolution efficiency (DE) values for $\mathrm{F} 8$ and $\mathrm{F} 9$ formulations were $75.94 \% \pm 0.23$ and
$83.04 \% \pm 0.50$, respectively, with $\mathrm{f} 2=40$. These results show that even with the two formulations presenting release profiles of 24 hours, there was no similarity between them and is still possible to obtain exclusive release profiles according to the pathological need by means of association of pharmaceutical units containing different kinetics of release.

Through the $2^{2}$ factorial experimental design, it was possible to evaluate qualitatively and quantitatively the statistically significant factors that influence the total time of release of the drug (100\%) in the dissolution profiles of the modified release PROP pellets. In the study, we evaluated the independent variables (HPMC and EC) and the interaction between these variables. The results obtained for the experimental design are listed in Table VI.

The highest value for the time of $100 \%$ drug release was obtained with F3 with smaller amount of soluble polymer HPMC $(2.00 \mathrm{mg})$ and greater amount of EC (30.00 mg), about $2400 \mathrm{~min}$. This may be an indication that under these conditions few pores were formed by the soluble polymer HPMC against a great amount of insoluble polymer EC, delaying the release. The lowest value for the time of $100 \%$ active compound release was obtained with formulation F2, with reverse condition, that is, a larger amount of HPMC $(6.00 \mathrm{mg})$ and smaller amounts of EC (30.00 mg). In this condition, the insoluble polymer EC, by being in smaller concentrations, had no significant effect on the PROP release. For the intermediate

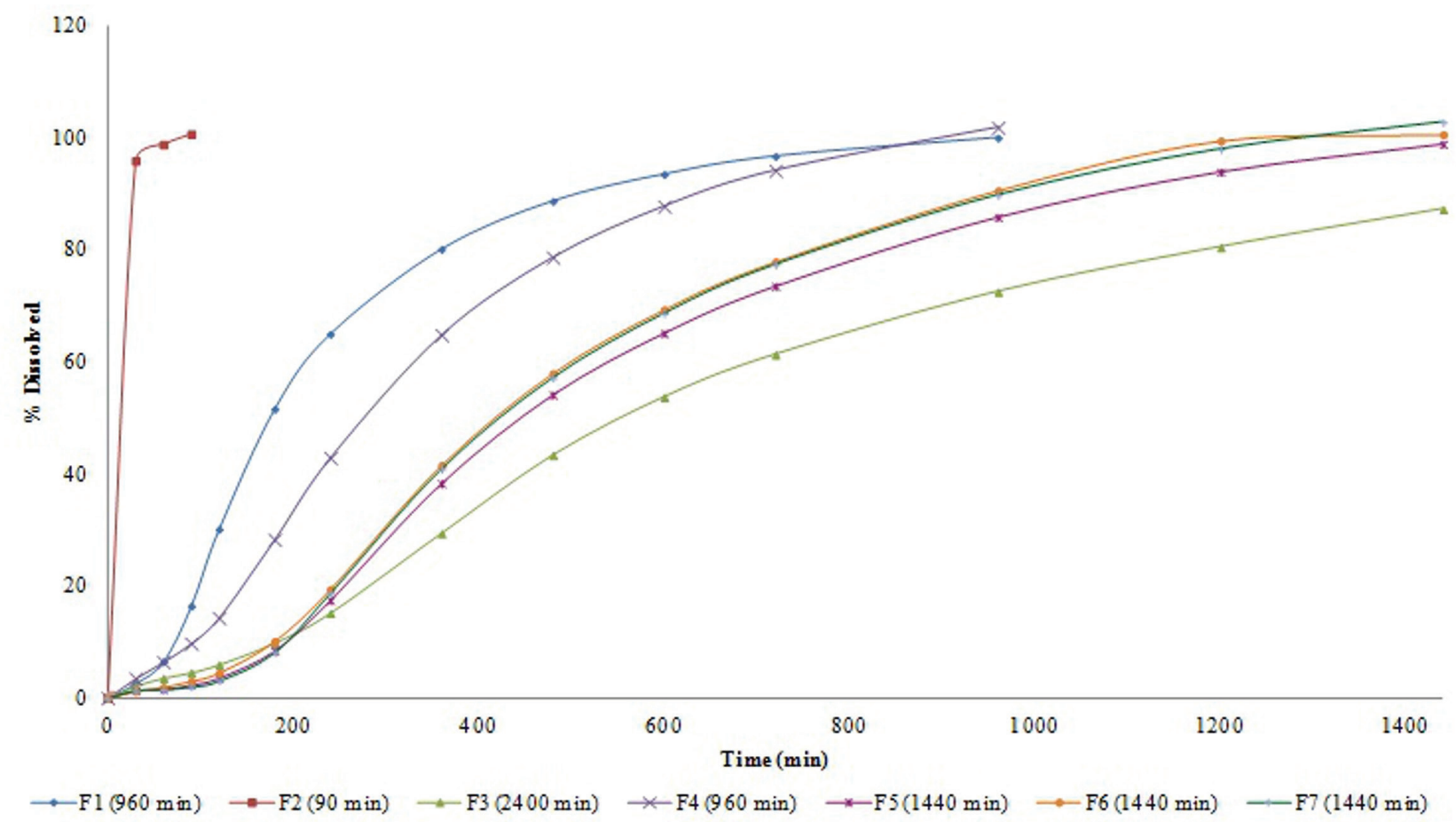

FIGURE 4 - Dissolution profiles of the formulations obtained in the experimental design. 


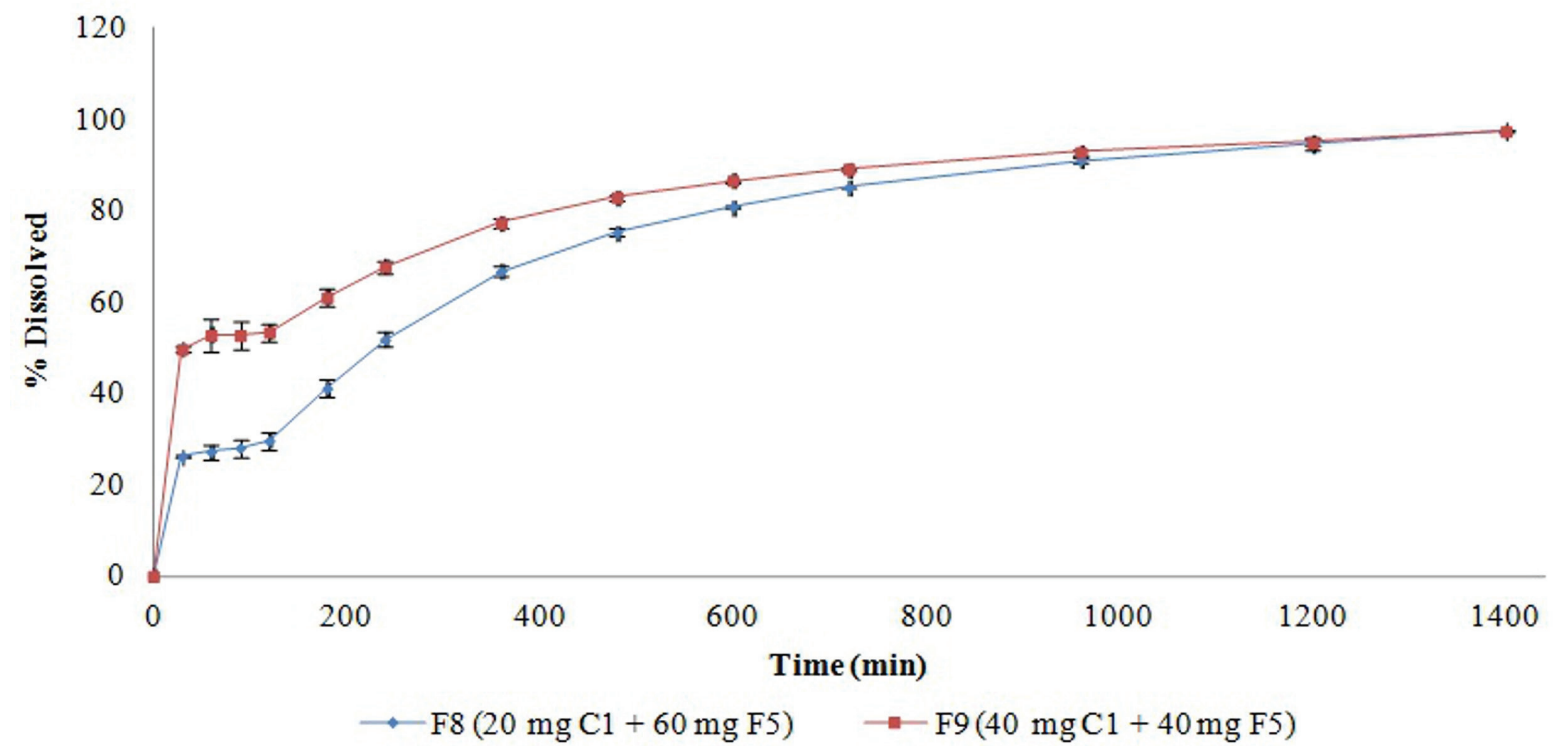

FIGURE 5 - F8 and F9 biphasic release profiles.

TABLE VI - Factorial experimental design $2^{2}$ for the variables HPMC (mg) and EC (mg) with triplicate at the center point and release response time $100 \%$ ( $\mathrm{min}$ ) for the release profile of the pellets of modified release PROP

\begin{tabular}{ccccc}
\hline & & \multicolumn{2}{c}{ Real Variables } & $\begin{array}{c}\text { Release } \\
\text { Time }\end{array}$ \\
\cline { 3 - 4 } Formulation & Sequence & $\begin{array}{c}\text { HPMC } \\
\text { (mg) }\end{array}$ & $\begin{array}{c}\text { EC } \\
\mathbf{( m g )}\end{array}$ & $\begin{array}{c}\mathbf{1 0 0 \%} \\
\text { (min) }\end{array}$ \\
\hline F1 & 4 & 2.00 & 10.00 & 960 \\
F2 & 3 & 6.00 & 10.00 & 90 \\
F3 & 5 & 2.00 & 30.00 & 2400 \\
F4 & 2 & 6.00 & 30.00 & 960 \\
F5 & 6 & 4.00 & 20.00 & 1440 \\
F6 & 1 & 4.00 & 20.00 & 1440 \\
F7 & 7 & 4.00 & 20.00 & 1440 \\
\hline
\end{tabular}

conditions, the release was between $960 \mathrm{~min}(\mathrm{~F} 4)$ and 1440 min (F5, F6 and F7), this last being considered the optimum point of the study reaching 24 hours of release.

The significance of the factors and model validation were evaluated through analysis of variance (ANOVA). It was possible to observe that both factors, HPMC and EC were significant for a linear model $(p<0.05)$. The interaction between the variables and the curvature of the model were not significant ( $p>0.05$ ). The results of $\mathrm{P}$-value $<0.05$ indicated that the model is valid at the significance level of $95 \%$.

The value of $\mathrm{R}^{2}=0.9705$ is in accordance with the $\mathrm{R}^{2} \mathrm{adj}=0.9508$, confirming this result. The linear model was constructed through the regression analysis, and describes the relationship between the significant independent variables and the response variable, as described below (equation 4), in which HPMC and EC are expressed in $\mathrm{mg}$ and the releasing time in minutes.

Realeasing time $100 \%=1102.50-[(288.75 \times$ HPMC $)+$ $(57.75 \times \mathrm{EC})]$

The positive coefficient for the amount of EC and negative for HPMC means that a greater amount of EC increases the dissolution time to reach a release of $100 \%$. On the other hand, a higher content of HPMC decreases this time. This is due to the solubility features of each polymer.

The outline map and the response surface for the $100 \%$ releasing time is shown in Figures $6 \mathrm{a}$ and $6 \mathrm{~b}$, respectively. There is no significant curvature, demonstrating that the linear model is valid.

The results obtained after the characterization analyses demonstrate that for the pellets used to obtain the biphasic formulations F8 and F9, both the AD and $\mathrm{CD}$ values are similar and that a percentage greater than $90.00 \%$ of these same pellets were retained between the 25-20 meshes (Table VII), evidencing good homogeneity of these parameters. All the samples presented moisture values lower than $5.00 \%$, specification recommended by Mehta et al. (2012) and friability $<0.40 \%$, indicating acceptable values according to the data present in the literature (Déo, Andreazza, Possamai , 2011). After the evaluation of the external morphology of the pellets (Figure 7), it was observed the smoothing of the $\mathrm{C} 1$ surface 

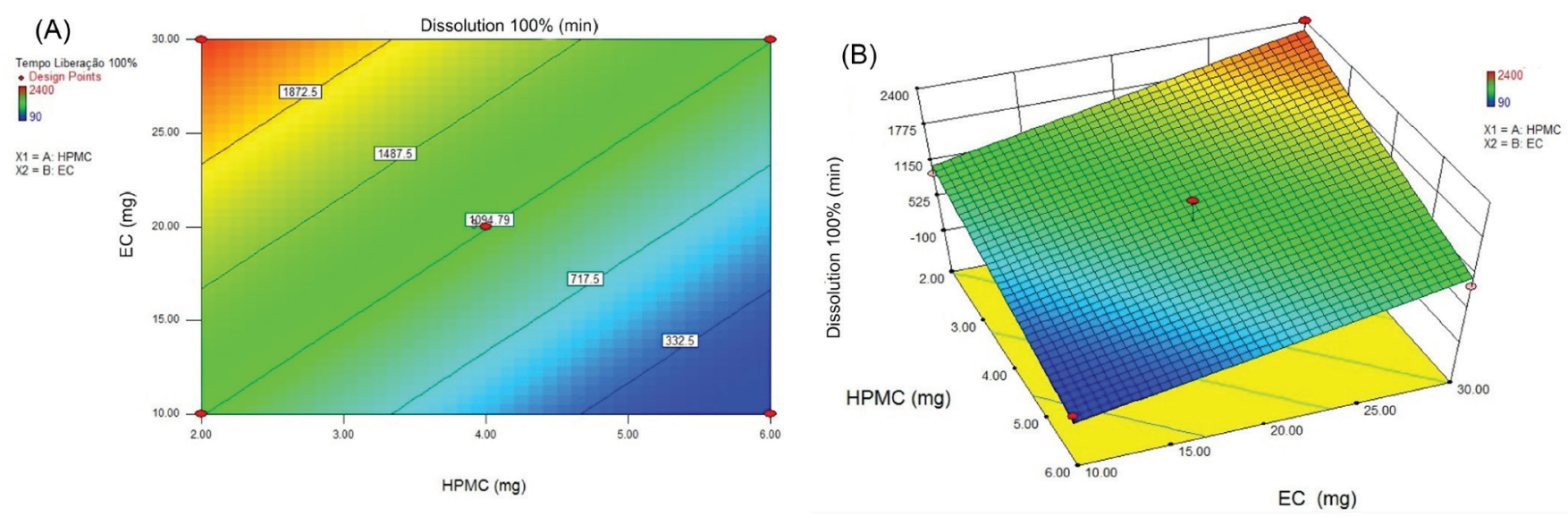

FIGURE 6 - Outline map A) and response surface B) for the experimental results of factorial experimental design $2^{2}$. Response release time $100 \%(\mathrm{~min})$ according to the amount of HPMC (mg) and EC (mg).
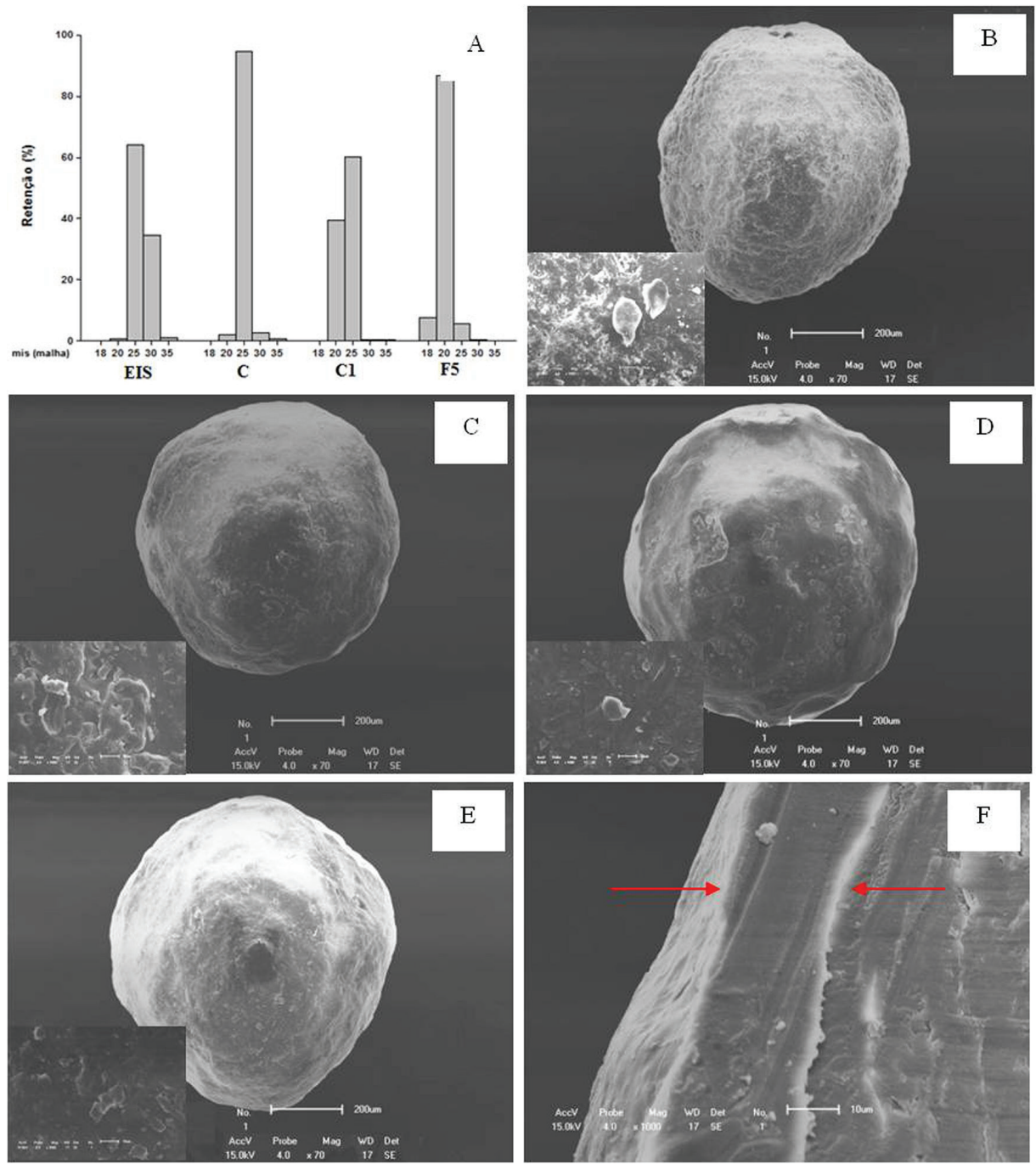

FIGURE 7 - Granulometric and external morphology analysis of pellets A) Granulometric analysis of the EIS and the pellets coated C, C1 and F5; B) Evaluation of the external morphology of the EIS in increase of 70x and 1000x; C) Evaluation of external morphology of $\mathrm{C}$ in increase of 70x and 1000x; D) External morphology evaluation of $\mathrm{C} 1$ in increase of 70x and 1000x; E) External morphology evaluation of F5 in increase of 70x and 1000x; F) Transversal image of F5 in increase of 1000x with emphasis in the coating layer of the pellet. 
TABLE VII - Characterization analyses of pellets obtained

\begin{tabular}{lcccc}
\hline \multirow{2}{*}{ Parameter } & \multicolumn{5}{c}{ Samples } & F5 \\
\cline { 2 - 5 } & EIS & C & 0.79 & 0.77 \\
$\mathrm{AD}(\mathrm{g} / \mathrm{mL})$ & 0.82 & 0.82 & 0.85 & 0.82 \\
$\mathrm{CD}(\mathrm{g} / \mathrm{mL})$ & 0.85 & 0.87 & $98.93 \pm 0.006$ & $99.02 \pm 0.009$ \\
Sphericity $\pm \mathrm{DP}$ & $98.07 \pm 0.012$ & $98.22 \pm 0.013$ & $1.17 \pm 0.10$ & $1.66 \pm 0.11$ \\
Loss by drying $(\%) \pm \mathrm{DP}$ & $3.09 \pm 0.12$ & $1.25 \pm 0.07$ & &
\end{tabular}

after sealing coating when compared to the surfaces EIS and $\mathrm{C}$ and homogeneity of the polymeric coating performed in F5.

Additionally, the thickness of the polymeric coating seems to be distributed uniformly throughout the surface of the pellet, which can be attributed to the good sphericity presented by the pellets (Table VII).

\section{CONCLUSION}

Thus, from our findings, it was possible to obtain a multiparticulate biphasic release system with the polymeric coating consisting of HPMC and EC, with quality within expected standards. The used $2^{2}$ factorial experimental design allowed the optimization of the development stage, once it resulted in the 24-hour desired releasing profile with a small number of experiments. Furhtermore, it was observed that the biphasic formulations F8 and F9, which are a combination of different releasing forms, ensure different releasing profiles, allowing the therapeutic adjustment according to the pathological needs.

\section{ACKNOWLEDGMENTS}

To CNPq/CAPES for the financial support and to pharmaceutical industry Prati Donaduzzi Ltda for providing the equipment and the necessary infrastructure to conduct part of this work.

To the Universidade Estadual de Maringá (UEM) for the SEM spectra.

\section{REFERENCES}

Aulton ME, Ortega GG. Delineamento de formas farmacêuticas. Porto Alegre: Artmed; 2008.

Bauer KH, Lehmann K, Osterwald HP, Rothgang G, Stanienda E. Coated Pharmaceutical dosage forms: fundamentals, manufacturing techniques, biopharmaceutical aspects, test methods, and raw materials. Stuttgart: CRC Press; 1998.
Brasil. Agência Nacional de Vigilância Sanitária. Resolução $\mathrm{n}^{\circ}$. 31, de 11 de agosto de 2010. Dispõe sobre a realização dos Estudos de Equivalência Farmacêutica e de Perfil de Dissolução Comparativo. Diário Oficial da União 12 ago 2010a; Seção 1:36-38.

Brasil. Agência Nacional de Vigilância Sanitária (ANVISA). Resolução n. 899, de 29 de maio de 2003. Determina a publicação do guia para validação de métodos analíticos e bioanalíticos. Diário Oficial da União 12 jun 2003; Seção 1: 56-59.

Brasil. Ministério da Saúde, Formulário Terapêutico Nacional [Internet]. Brasília (DF): Ministério da Saúde, 2010b. [citado 2017 Mar 14]. (Série B. Textos Básicos de Saúde). Available on: http://bvsms.saude.gov.br/bvs/publicacoes/formulario terapeutico_nacional_2010.pdf.

Bruschi ML. Strategies to Modify the Drug Release from Pharmaceutical Systems. Cambridge: Woodhead Publishing Limited; 2015.

Costa P, Lobo JM. Modeling and comparison of dissolution profiles. Eur J Pharm Sci. 2001;13(2):123-133.

Dallmann R, Brown SA, Gachon F. Chronopharmacology: new insights and therapeutic implications. Ann Rev Pharmacol Toxicol. 2014;54:339-361.

Déo SC, Andreazza IF, Possamai JC. Development of mesalazine pellets coated with methacrylic-derived polymer. Braz J Pharm Sci. 2011;47(1):103-109.

European Pharmacopoeia. 7 ed. Strasbourg: Council of Europe; 2011. p.318-319.

Farmacopeia Brasileira. 5.ed. São Paulo: Atheneu; 2010.

Ghebre-Selassie I. Pellets: A general overview. In: Pharmaceutical pelletization technology. New York: Marcel Dekker; 1989. 
Guerra-Ponce WL, Gracia-Vásquez SL, González-Barranco P, Camacho-Mora IA, Gracia-Vásquez YA, Orozco-Beltrán $\mathrm{E}$, et al. In vitro evaluation of sustained released matrix tablets containing ibuprofen: a model poorly water-soluble drug. Braz J Pharm Sci. 2016;52(4):751-759.

Jha MK, Rahman MH, Rahman MM. Biphasic oral solid drug delivery system: A review. Int J Pharm Sci Res. 2011;2(5):11081115.

Khan KA. The concept of dissolution efficiency. J Pharm Pharmacol. 1975;27(1):48-49.

Kulkarni PK. Pelletization techniques as a pharmaceutical tool in the multiparticulate drug delivery system: a review. Int. J. Drug Formulation Res. 2010;1(1):89-118.

Lachman L, Lieberman HA, Kaning JL. The theory and practice of industrial pharmacy. 4th ed. India: CBS Publishers \& Distributors; 2013.

Liltorp K, Larsen TG, Willumsen B, Holm, R. Solid state compatibility studies with tablet excipients using non thermal methods. J Pharm Biomed Anal. 2011;55(3):424-428.

Lin SY, Kawashima Y. Current status and approaches to developing press-coated chronodelivery drug system. J Control Release. 2012;157(3):331-353.

Londhe S, Gattani S, Surana S. Development of floating drug delivery system with biphasic release for verapamil hydrochloride: in vitro and in vivo evaluation. J Pharm Sci Technol. 2010;2(11):361-367.

Lopes CM, Lobo JM, Costa P. Formas farmacêuticas de liberação modificada: polímeros hidrifílicos. Rev Bras Cienc Farm. 2005;41(2):143-154.

Lovgren K, Lundberg PJ. Determination of sphericity of pellets prepared by extrusion/spheronization and the impact of some process parameters. Drug Dev Ind Pharm. 1989;15(1416):2375-2392.

Maggio RM, Castellano PM, Kaufman TS. A new principal component analysis-based approach for testing "similarity" of drug dissolution profiles. Eur J Pharm Sci. 2008;34(1):67-77.

McGinity JW, Felton LA. Aqueous polymeric coatings for pharmaceutical dosage forms. New York: CRC Press; 2008.
Mehta S, De Beer T, Remon JP, Vervaet C. Effect of disintegrants on the properties of multiparticulate tablets comprising starch pellets and excipient granules. Int J Pharm. 2012;422(1):310317.

Ohdo S. Chronotherapeutic strategy: rhythm monitoring, manipulation and disruption. Adv Drug Deliver Rev. 2010;62(9):859-875.

Oliveira RB. Polímeros na obtenção de sistemas de liberação de fármacos. Rev. Eletronica Farm. 2007;3(1):29-35.

Pezzini BR, Silva MA, Ferraz HG. Formas farmacêuticas sólidas orais de liberação prolongada: sistemas monolíticos e multiparticulados. Rev Bras Cienc Farm. 2007;43(4):491-502.

Pisano GP. The development factory: unlocking the potential of process innovation. Boston: Harvard Business School; 1997.

Prasad MB, Vidyadhara S, Sasidhar RLC, Balakrishna T, Trilochani P. Development and evaluation of diltiazem hydrochloride controlled-release pellets by fluid bed coating process. J Adv Pharm Techonol Res. 2013;4(2):101-107.

Rowe RC, Sheskey PJ, Quinn ME. Handbook of Pharmaceutical Excipients. 6th ed. USA: Pharmaceutical Press; 2009.

Rubin EA, Tummala S, Both DA, Wang C, Delaney EJ. Emerging technologies supporting chemical process R\&D and their increasing impact on productivity in the pharmaceutical industry. Chem Rev. 2006;106(7):2794-2810.

Saeedi M, Morteza-Semnani K, Sagheb-Doust M. Evaluation of Plantago major L. seed mucilage as a rate controlling matrix for sustained release of propranolol hydrochloride. Acta Pharm. 2013;63(1):99-114.

Sahoo J, Murthy PN, Biswal S, Sahoo SK, Mahapatra AK.Comparative study of propranolol hydrochloride release from matrix tablets with Kollidon SR or hydroxy propyl methyl cellulose. AAPSPharmSciTech. 2008;9(2):577-582.

Singh B, Kumar R, Ahuja N. Optimizing drug delivery systems using systematic" design of experiments." Part I: fundamental aspects. Crit Rev Ther Drug Carrier Syst. 2005;22(1):27-105.

Srikanth MV, Rao NS, Sunil SA, Ram BJ, Kolapalli VRM. Statistical design and evaluation of a propranolol $\mathrm{HCl}$ gastric floating tablet. Acta Pharm Sin B. 2012;2(1):60-69. 
Tiţa B, Fuliaş A, Bandur G, Marian E, Tiţa D. Compatibility study between ketoprofen and pharmaceutical excipients used in solid dosage forms. J Pharm Biomed Anal. 2011;56(2):221-227.

Verdecchia P, Angeli F, Mazzotta G, Garofoli M, Romundo E, Gentile G, et al. Day-night dip and early-morning surge in blood pressure in hypertension prognostic implications. Hypertension. 2012;60(1):34-42.
Villanova JC, Oréfice RL, Cunha AS. Pharmaceutical applications of polymers. Polímeros. 2010;20:51-64.

Zerbini AP, Ferraz HG. Sistemas multiparticulados: minicomprimidos. Rev Cienc Farm Básica Apl. 2011;32(2):149158.

Received for publication on $04^{\text {th }}$ May 2017 Accepted for publication on $19^{\text {th }}$ February 2018 